\title{
Fatigue Failure Load of Molars with Thin-Walled Prosthetic Crowns Made of Various Materials: A 3D-FEA Theoretical Study
}

This article was published in the following Dove Press journal: Clinical, Cosmetic and Investigational Dentistry

\author{
Noor Al Mortadi ${ }^{1}$ \\ Khaled Bataineh ${ }^{2}$ \\ Mohammad Al Janaideh ${ }^{2}$ \\ 'Department of Applied Dental Sciences, \\ Jordan University of Science and \\ Technology, Irbid, Jordan; ${ }^{2}$ Department of \\ Mechanical Engineering, Jordan University \\ of Science and Technology, Irbid, Jordan
}

Purpose: The aim of the study was to compare the fatigue lifetime of thin-walled molar crowns made of all-ceramic CAD/CAM materials under three different cyclic load conditions.

Methods: The crowns were fatigued using a range of forces similar to which crowns in the molar region might be subjected. Crowns of two thin-walled thicknesses $(0.7 \mathrm{~mm}$ and $1.1 \mathrm{~mm}$ ) were prepared from Zirconia and lithium disilicate. Numerical methodologies to simulate the behavior of a restored tooth were applied to evaluate the fatigue lifetimes under multiple cyclic loading; $50 \mathrm{~N}, 100 \mathrm{~N}, 150 \mathrm{~N}$. An $8 \mathrm{~mm}$ hemispherical indenter was used to simulate the mechanical stress of opposing teeth during mastication, and applied the fatigue load at the center of the crowns.

Results: The results show that the predicted survival rates for $0.7 \mathrm{~mm}$ and $1.1 \mathrm{~mm}$ Zirconia crowns were not significantly different. The number of life cycles predicted for Zirconia under all fatigue loads indicates that these crowns can live longer than five clinical years (when crowns are in service). However, crowns made from lithium disilicate also can be predicted to survive longer than five clinical years (under load up to $100 \mathrm{~N}$ ). Crowns made of lithium disilicate should have $1.1 \mathrm{~mm}$ thickness to survive longer than five clinical years (when crowns are in service).

Conclusion: Zirconia crowns exhibit significantly higher fracture resistance compared with lithium disilicate crowns, making them better suited to handle higher masticatory loads encountered in the posterior region of the mouth. Lithium disilicate can survive more than five clinical years (when their thickness is $1.1 \mathrm{~mm}$ ).

Keywords: dental materials, restored crown, CAD/CAM, all-ceramics, mechanical loads, mastication

\section{Introduction}

Ideally, crowns are used to restore the natural teeth due to many reasons, such as tooth loss, discoloration, extensive dental caries, broken teeth and improving the shape of the teeth. Different materials are used in restored teeth, divided into metal, ceramic fused with metal or all-ceramic crowns. All-ceramic restorations have several favorable characteristics such as life-like appearance, ${ }^{1}$ biocompatibility, ${ }^{2}$ wear resistance, and color stability. ${ }^{3}$ However, the drawbacks include less-thanideal marginal adaptation, excessive wear of the opposing dentition, aggressive preparation design, ${ }^{1}$ technique sensitivity, ${ }^{4}$ and susceptibility to fracture.

Moreover, it is reported that most all-ceramic restorations have high clinical failure rates especially if they are placed on posterior teeth. ${ }^{5-7}$ The brittleness of
Correspondence: Noor Al Mortadi Department of Applied Dental Sciences, Jordan University of Science and Technology, P.O. Box (3030), Irbid 22110, Jordan

Tel +9627201000

Email naalmortadi@just.edu.jo 
these materials stands as a barrier against their widespread use in the posterior teeth. ${ }^{8}$ In order to overcome the failure behaviors, several restorative materials have been developed recently. For instance, all-ceramic crowns manufactured by Computer Aided Design/Computer Aided Manufacturing (CAD/CAM) were developed to offer increased strength and favorable homogenous structure, to improve the retention and longevity of the restorations. $^{9-11}$

The most common all-ceramic CAD/CAM materials are Zirconia and lithium disilicate, ${ }^{12}$ with lithium disilicate having higher translucency and lower mechanical strength than Zirconia. ${ }^{13}$ Zirconia is an attractive choice for use in tooth restoration due to its aesthetic appeal, biocompatibility, and high flexural strength. ${ }^{14,15}$ The flexural strength of Zirconia ranges from 650 to $1200 \mathrm{MPa}^{8}$ and it is comparable to ceramic fused to metal in shear strength. ${ }^{16}$ Zirconia has been used for constructing a full arch restoration. ${ }^{17}$ Literature reported the thickness of the core has a significant effect on the hardness, fracture toughness, and residual stress for crowns made from Zirconia. ${ }^{18,19}$

On the other hand, lithium disilicate is widely used as modern $\mathrm{CAD} / \mathrm{CAM}$ material. It has superior aesthetic properties and color stability. ${ }^{20}$ Thus it can be used for the anterior region. ${ }^{21}$ One concern regarding lithium disilicate is that it is not strong enough to be used for restoring the posterior teeth due to its brittleness and susceptibility to fracture. ${ }^{22}$ The fracture resistance of Zirconia crowns under a variety of conditions has been studied previously. ${ }^{23}$

The long-term success and the survival rate of restorative materials mainly depend on their mechanical properties, such as fatigue failure, magnitude and type of occlusal loads and the thickness of the crown. It is advised to preserve the abutment tooth by minimal invasive preparation together with a minimal thickness of the restored crown to provide adequate fatigue resistance. The excessive removal of tooth structure may cause potential damage to dental pulp, ${ }^{24}$ and perhaps reduce the stability of the prepared tooth structure (abutment). ${ }^{25}$ The thickness of the restored crown is thought to have a significant effect on the stability of the restoration (Thompson). ${ }^{23}$ In general, the guidelines of tooth preparation require an axial and occlusal tooth reduction of about $1.5-2.0 \mathrm{~mm}^{18}$ to ensure the stability of the restored crown. ${ }^{19}$

A review conducted in 2015 concluded that no evidence could be retrieved for the minimal occlusal clearance necessary to provide sufficient thickness of the subsequent restoration. However, the review assumed that $1.5 \mathrm{~mm}$ for all-ceramic restorations are usually taught values in this regard, which are also often specified in manufacturers' instructions. In addition, no specific type of finish line has been clearly proven to be superior to others. $^{25}$ A rounded internal geometry is a crucial prerequisite to all-ceramic restorations to avoid tensile stress; otherwise, fractures of the brittle material are expected. ${ }^{25}$ The rounded design has proved to be superior. ${ }^{26}$

The ability of a cemented crown to withstand dislodging forces is determined by three geometric aspects: height, the height to base ratio, and preparation taper. The minimum stump height is $3-4 \mathrm{~mm}^{27,28}$ and a height to base ratio of 0.4 is needed to provide adequate resistance. $^{29-31}$ A preparation taper of less than $5^{\circ}$ is unfavorable for the $\mathrm{CAD} / \mathrm{CAM}$ production process since scanning devices have difficulties in detecting nearly vertical surfaces. ${ }^{32}$ Additionally, tapers from $5^{\circ}$ to $10^{\circ}$ are favorable as retention decreases for tapers smaller than $5^{\circ}$ or greater than $10^{\circ} .{ }^{33,34}$ However, preparations for allceramic restoration with greater taper are more resistant to fractures. ${ }^{35-37}$

Upon insertion, in order to be properly seated into position, the restoration must have an even luting cement film thickness of $\sim 25-50 \mu \mathrm{m}$ at the $\operatorname{margin}^{38,39}$ to achieve marginal accuracy and ensure clinical reliability.

As a response, a large number of fatigue studies have focused on simplified static fatigue (constant load) of the restorative materials. This axial occlusal load at a single point generates values of stress distribution on the crowns that is different to what is occurring in the oral mouth due to intraoral mastication and chewing cycle. It is worth mentioning that the commonly used static fatigue loads that apply on the crown until fracture do not offer valuable clinical information. Hence, a fatigue test is preferred to be evaluated under cyclical fatigue loads (dynamic load) to simulate the actual clinical chewing cycle and masticatory stresses. Some terms are very common when a computational method is used such as stress and stress concentration. Stress consists of the response of the atoms and molecules to a load applied in the evaluated structure. $^{40}$

Monolithic Zirconia crowns of occlusal thickness of $0.5 \mathrm{~mm}$ showed sufficient strength to be used in the posterior teeth. ${ }^{41-43}$ The stability of the restoration is reported to be influenced by the type of cement used. ${ }^{41,44,45}$ Cement is an adhesive bonding material that improves the fracture resistance of monolithic all-ceramic crowns. ${ }^{46}$ However, 
others reported that $0.5 \mathrm{~mm}$ monolithic crowns possessed sufficient strength to endure physiologic performance, regardless of the type of cementation and the fracture strength of $0.2 \mathrm{~mm}$ cemented crowns was too low for clinical application. ${ }^{47}$

To date, there is a very limited number of studies on the relationship between all-ceramic crown thickness and survival rate. Numerical simulations using Finite Element Analysis (FEA) can be effectively used to predict the fatigue life of minimum all-ceramic crown thicknesses under different clinical loading conditions. However, it has been believed that all-ceramic restorations require extensive tooth preparation.

The purpose of this study is to test the hypothesis that thin-walled all ceramic CAD/CAM crowns made from Zirconia or lithium disilicate can withstand cyclic stresses generated from masticatory forces. The study is testing the fatigue resistance of thin-walled all-ceramic crowns. The fatigue life representing the number of cycles to failure of the crowns is estimated using FEA.

\section{Materials and Methods}

A die of mandibular first molar made from gypsum (Model Plaster, 20 LB, White, Dentsply Sirona) was scanned using a Sirona scanner (Sirona scanner, inlab SW 16.1) and fabricated to fit a preparation with 1.5- to 2.0-mm occlusal reduction. The abutment was prepared in a reduced occlusal surface, with a chamfer margin width of $1.00 \mathrm{~mm}$, and possessed an axial surface height of approximately $5 \mathrm{~mm}$ (4.83 at mesiobuccal cusp and 4.92 at distobuccal cusp) with $8^{\circ}$ taper. A workflow of the method followed in this study is explained in Figure 1.

The scanned data were exported as a stereolithography (STL) file to Sirona software in order to design the full contour of restored crown. The thickness of the cement layer was set in the software as $50 \mu \mathrm{m}$. Two designs were prepared for the thin-walled crowns for each material; Group A: ultrathin of average thickness $0.7 \mathrm{~mm}$ and Group B: thin of average thickness $1.1 \mathrm{~mm}$ (Figure 2). The measurements of the crowns at different areas are represented in Table 1.

The STL files for the crowns and the die were converted into solid models using solid modeling software (SolidWorks 2018, DS Solidworks Corp, USA) to produce the $3 \mathrm{D}$ model to be used for FEA. The mechanical properties were set for the components of the 3D model including the CAD/CAM materials used for crowns ${ }^{48,49}$
(Table 2). The crowns were made from two different materials, Zirconia and lithium disilicate.

Several Boolean operations were applied to assure the interfacial mesh congruence. This step ensured the crowns were set correctly on the corresponding die. Then the assembly of the crown and corresponding die were transferred into Finite Element Analysis software package (ANSYS 18. 1, Inc., USA) for testing the fatigue behavior of the all-ceramic crowns.

As part of the 3D model, a hemispherical indenter (8 $\mathrm{mm}$ diameter) was made in order to apply the cyclic load on the center of the crown (Figure 3). The mechanical properties were set to simulate the enamel of the opposing teeth. The root was fixed and supported in all dimensions in order to apply the compressive fatigue force by indenter (Figure 4).

The frictional contact between occlusal surface of the crown and indenter was simulated using FEA software. The exact values for friction coefficient are difficult to obtain, so the authors assumed 0.3 for friction, which is a conservative value. The indenter was applied axially on the occlusal surface of the crowns using two cyclic loadings; axial loading and axial loading with $0.8 \mathrm{~mm}$ sliding in $\mathrm{Z}$ axis towards the buccal surface. The indenter contacted the occlusal surface at three points; distobuccal cusp, mesiolingual cusp and distolingual cusp, in agreement with the literature (Figure 5). The latter cyclic loading was applied on occlusal surface to accurately simulate the chewing process in the clinical mouth.

The minimum compressive load on two thin-walled crowns was $5 \mathrm{~N}$ and the maximum was the variable for this study, to estimate the fatigue test, as follows;

Level 1: minimum load: $5 \mathrm{~N}$; maximum load: $50 \mathrm{~N}$, mean level $=27.5 \mathrm{~N}$

Level 2: minimum load: $5 \mathrm{~N}$; maximum load: $100 \mathrm{~N}$, mean level $=52.5 \mathrm{~N}$

Level 3: minimum load: $5 \mathrm{~N}$; maximum load: $150 \mathrm{~N}$, mean level $=77.5 \mathrm{~N}$

The static FEA which was obtained from previous studies were post-processed with fatigue stress-life ( $\mathrm{S}-$ $\mathrm{N})$ behaviors. $^{49}$ A curve of $\mathrm{S}-\mathrm{N}$ represents the stress amplitude $(\sigma a)$ as a function for the number of cycles until failure $\left(\mathrm{N}_{\mathrm{f}}\right)$. However, the current study used a combination of $\mathrm{S}-\mathrm{N}$ behavior and FEA under cyclic loading for the crown materials. The life cycle of for Zirconia is (1000, 308.1890979) and lithium disilicate (1000, 88.2204892) (Figure 6). Linear isotropic models are used 


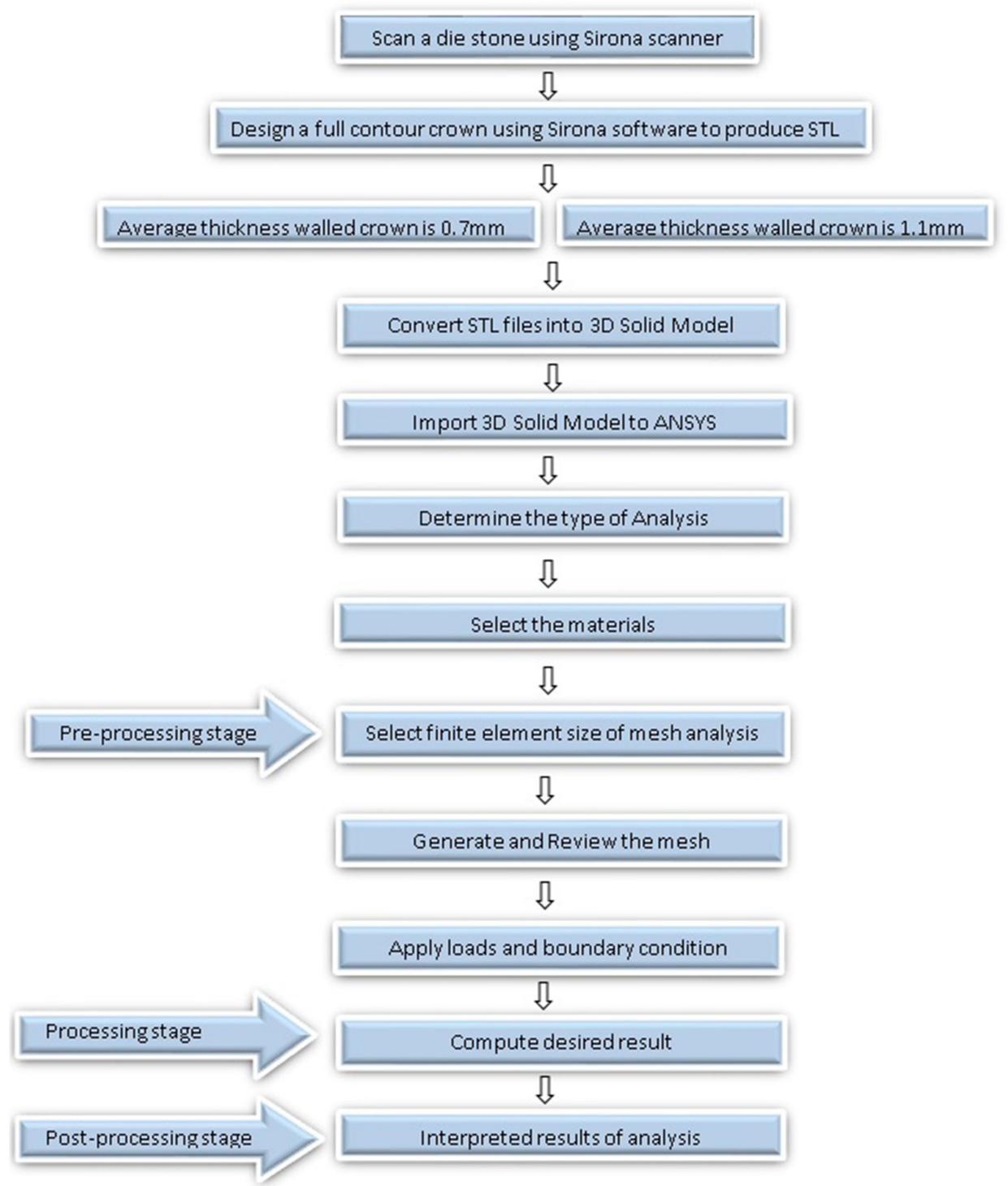

Figure I The flowchart of the methodology.
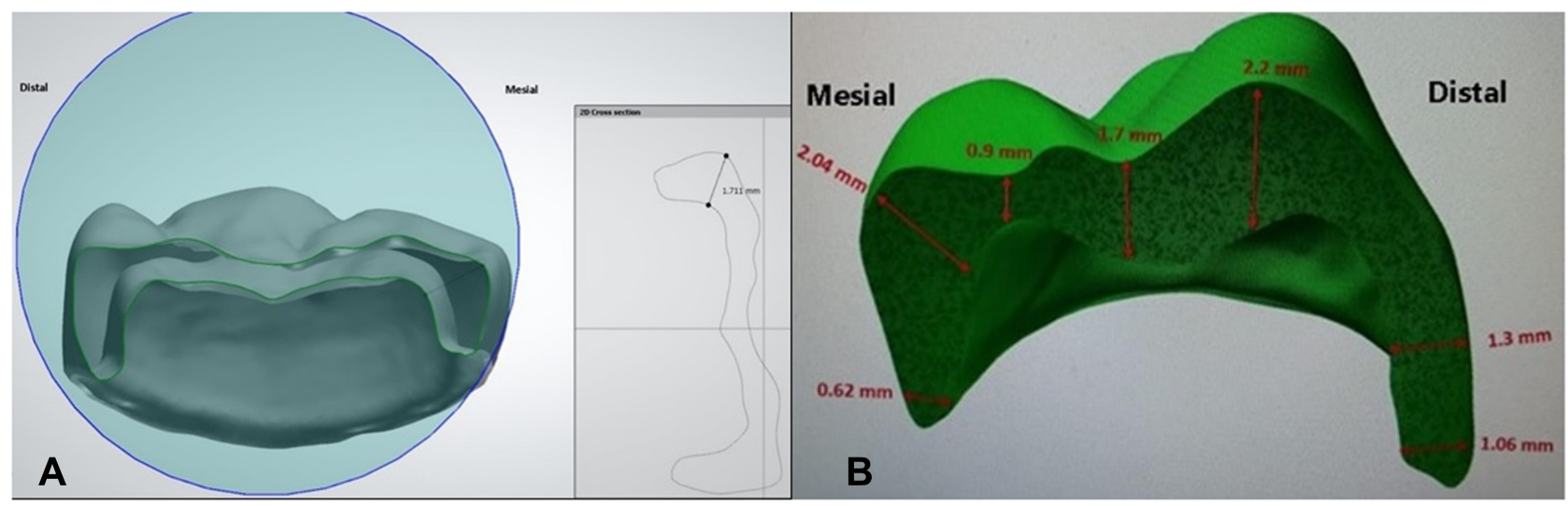

Figure 2 Thickness of experimental crown of (A) group A at mesio occlusal point; (B) group B at different areas. 
Table I The Thickness of Experimental Crowns at Different Areas

\begin{tabular}{|l|l|l|l|l|l|l|l|}
\hline Group & $\begin{array}{l}\text { Crown } \\
\text { Type }\end{array}$ & $\begin{array}{l}\text { Mesial } \\
\text { Gingivally }\end{array}$ & $\begin{array}{l}\text { Mesial } \\
\text { Occlusally }\end{array}$ & $\begin{array}{l}\text { Midpoint } \\
\text { Fossa }\end{array}$ & $\begin{array}{l}\text { Distal } \\
\text { Gingivally }\end{array}$ & $\begin{array}{l}\text { Distal } \\
\text { Occlusally }\end{array}$ & $\begin{array}{l}\text { Average of } \\
\text { Thickness }\end{array}$ \\
\hline Group A & Ultra thin & 0.4 & 1.7 & 0.4 & 1.2 & 0.37 & $\mathbf{0 . 7}$ \\
Group B & Thin & 0.62 & 2.04 & 1.7 & 2.2 & 1.06 & $\mathbf{I . 1}$ \\
\hline
\end{tabular}

Table 2 Mechanical Properties for the Materials Used in the FEA

\begin{tabular}{|l|l|l|l|l|l|}
\hline Material & $\begin{array}{l}\text { Young's Modulus } \\
(\mathbf{G P a})\end{array}$ & $\begin{array}{l}\text { Poisson } \\
\text { Ratio (v) }\end{array}$ & $\begin{array}{l}\text { Flexural } \\
\text { Strength (MPa) }\end{array}$ & $\begin{array}{l}\text { Compressive } \\
\text { Strength (MPa) }\end{array}$ & $\begin{array}{l}\text { Shear Strength } \\
(\mathbf{M P a})\end{array}$ \\
\hline Indenter/opposing tooth $^{48}$ & 84.1 & 0.33 & 11.5 & 384 & 60 \\
Lithium Disilicate $^{48}$ & 95.9 & 0.23 & 356.7 & - & - \\
Zirconia $^{48}$ & 210 & 0.32 & 900 & - & - \\
Dentine/abutment $^{49}$ & 18.6 & 0.31 & 105.5 & 267 & $12-138$ \\
Dual cure resin/Adhesive cement $^{49}$ & 8 & 0.3 & - & - & 34.4 \\
\hline
\end{tabular}

to describe the mechanical behaviors of the materials used in the study.

It is important to consider the density of the mesh used in the FEA model as the finer mesh density gives accurate measurements for the analysis. A finer mesh density was generated at the occlusal surface of the crown due to the highly complex features of the surface (Figure 7). The number of elements of the FEA model was 184,564 fournode tetrahedron element using mesh convergence test. This number indicates that no change can happen to the measurements if a further number of elements created.

The crowns were assumed to perfectly bond to abutment to ensure the maximum retention of the crowns and to avoid any movement which could adversely affect the fatigue test. FEA was used to predict and determine the areas of maximum stress distributions on the tooth surface which could lead to crown failure or cracks. The fatigue life was calculated to predict the survival life rate of the experimental materials.

\section{Results}

Finite element simulations were carried out to evaluate the fatigue resistance of different thicknesses of thin-walled all ceramic $\mathrm{CAD} / \mathrm{CAM}$ crowns. Once the mesh density of the 3D model in FEA was determined, the maximum tensile stress on occlusal surface of the crowns could be determined. Among the experiment groups, the fatigue life reached the highest for group $\mathrm{B}$ made from Zirconia under axial loading at $50 \mathrm{~N}, 100 \mathrm{~N}$, and $150 \mathrm{~N}$ compared with all other groups of the experiment materials (Table 3 ). The maximum tensile stress for this group under axial load of $50 \mathrm{~N}$ and $150 \mathrm{~N}$ was $43.493 \mathrm{MPa}$ and $82.482 \mathrm{MPa}$, respectively (Figure 8). However, the maximum tensile stress for lithium disilicate at $50 \mathrm{~N}$ and $150 \mathrm{~N}$ was 35.557 $\mathrm{MPa}$ and 72.144 $\mathrm{MPa}$, respectively (Figure 9). The figures show the maximum tensile stress at distobuccal cusp. This is expected as this area occludes with the palatal side of the upper teeth.

The plot shows the fatigue life of experimental crowns under axial loading, and axial loading with sliding (Figure 10). The fatigue life for axial loading for group A made from lithium disilicate is 3.605.271 and 653.814 .4 at $50 \mathrm{~N}$ and $100 \mathrm{~N}$, respectively. However, the crown was fractured at $120 \mathrm{~N}$ and it was not possible to test it in fatigue test level 3 at $150 \mathrm{~N}$. This material showed the lowest fatigue life among the experiment groups. According to levels of fatigue test of this study, the fatigue behaviors for the group A can withstand fatigue test up to $100 \mathrm{~N}$.

The life cycle for group A made from lithium disilicate is 2,157,587.52 while for group A made from Zirconia it is $2,157,587.52$ under axial load $100 \mathrm{~N}$ (Table 3). It is worth mentioning that life cycles for Zirconia and lithium disilicate reduce to $653,814.4$ and 674,821 , respectively under the fatigue test with 0.8 sliding.

The factor of safety guarding against fatigue failure were predicted using FEA. It is reported that the loading protocol that simulates five clinical years is 250,000 cycles and this simulates one year of clinical service. ${ }^{50}$ Thus group B of Zirconia crowns has the highest factor of life which is 15 . However, group A of lithium disilicate crowns has the lowest factor of life which is 1.1 . 


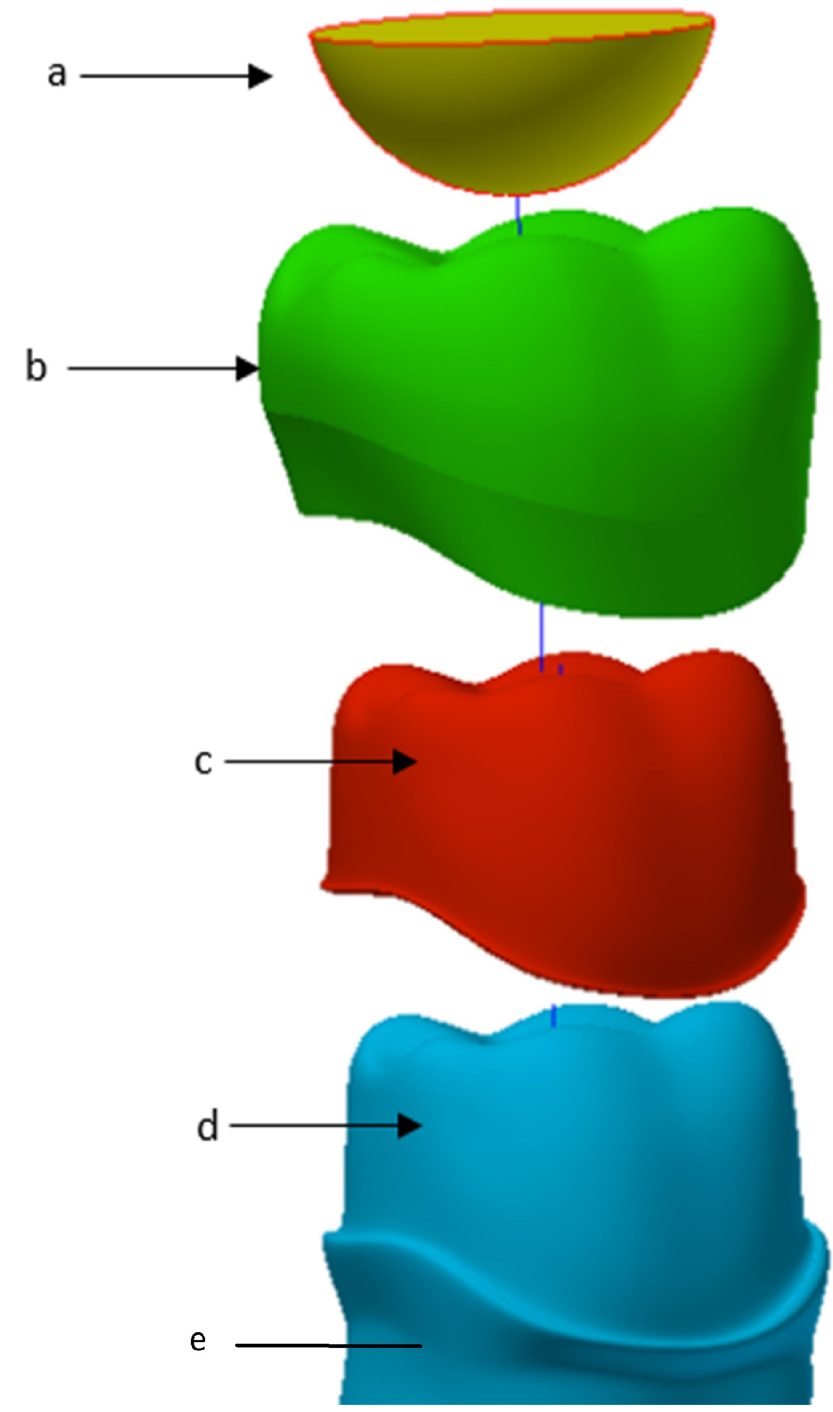

Figure 3 Materials of FEA model; (A) indenter/opposing tooth of enamel (B) crown (C) cement (D) abutment/Dentine (E) root.

The maximum shear stress at the dentin-adhesive interface at the static load is located on the distobuccal cusp (Figure 11). The maximum shear stress under load of 100 $\mathrm{N}$ for group A of Zirconia is $4.5 \mathrm{MPa}$, while it is $4.4 \mathrm{MPa}$ for group A made of lithium disilicate (Table 4). This means the magnitudes of shear stress are clearly far away from the shear strength of the dual resin adhesive material (34.4 MPa).

\section{Discussion}

In order to evaluate the stress distribution generated by masticatory loads in the restored crown, FEA has been used due to specimen standardization, low cost, and because it is a numerical method that offers a means to find an approximate explanation. ${ }^{51-54}$

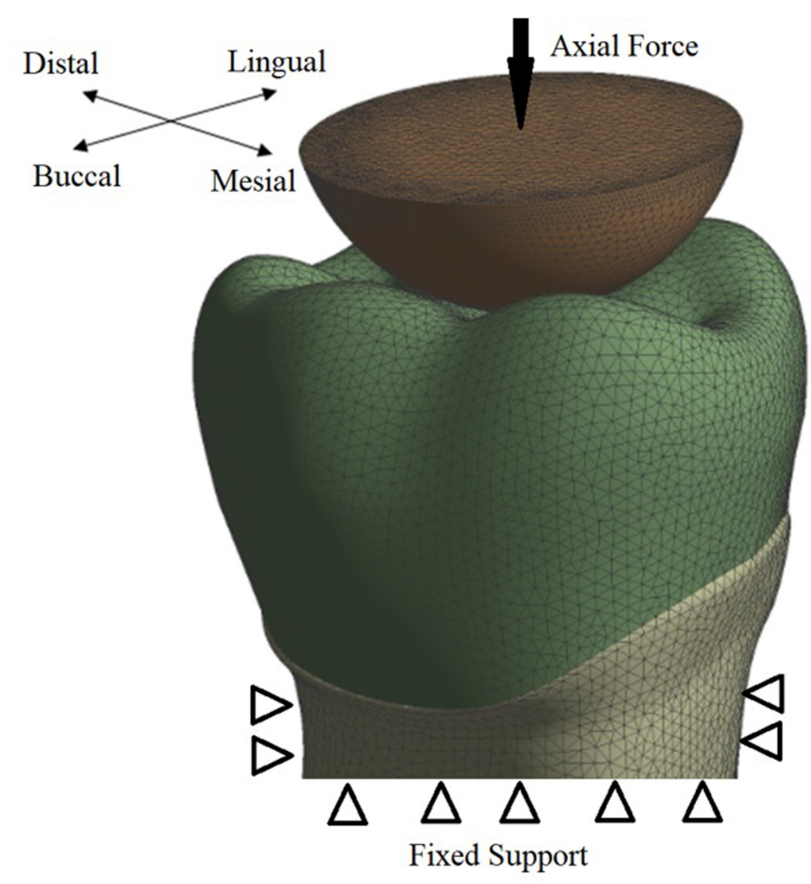

Figure 4 The boundary conditions and the direction of applied load on the crown.

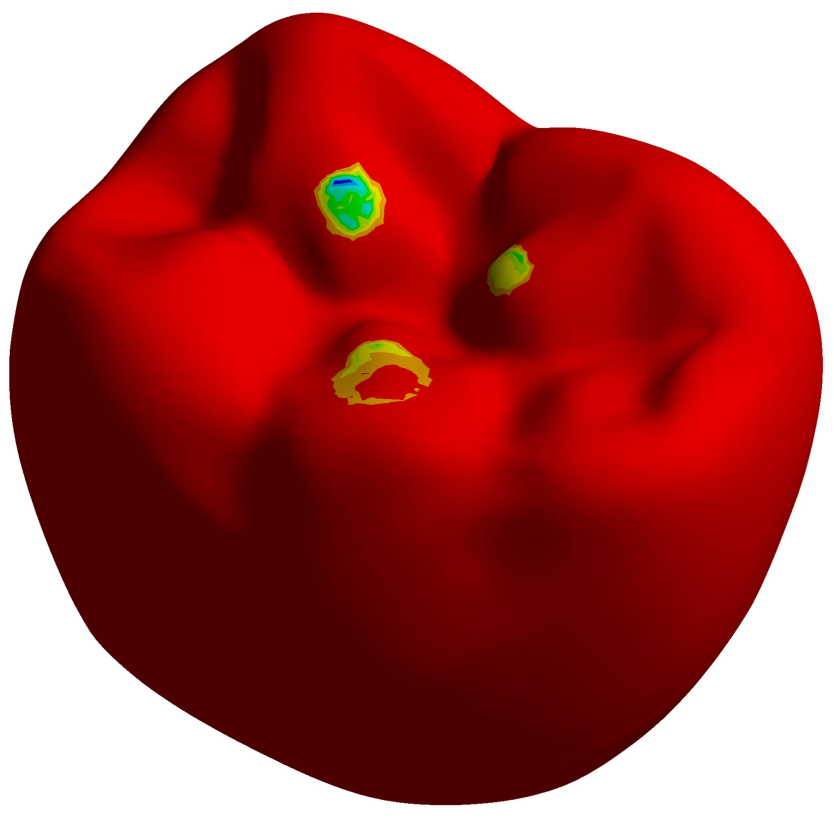

Figure 5 The three points of indenter contacting the occlusal surface.

Moreover, the FEA method has been successfully used in biomechanical applications of dentistry and found to be a very attractive tool because it can easily deal with complex geometry, complex material behavior and complex loading conditions that are usually found in the oral cavity, ${ }^{5-57}$ as well as to assess new dental designs before conducting complex in vivo experiments. 


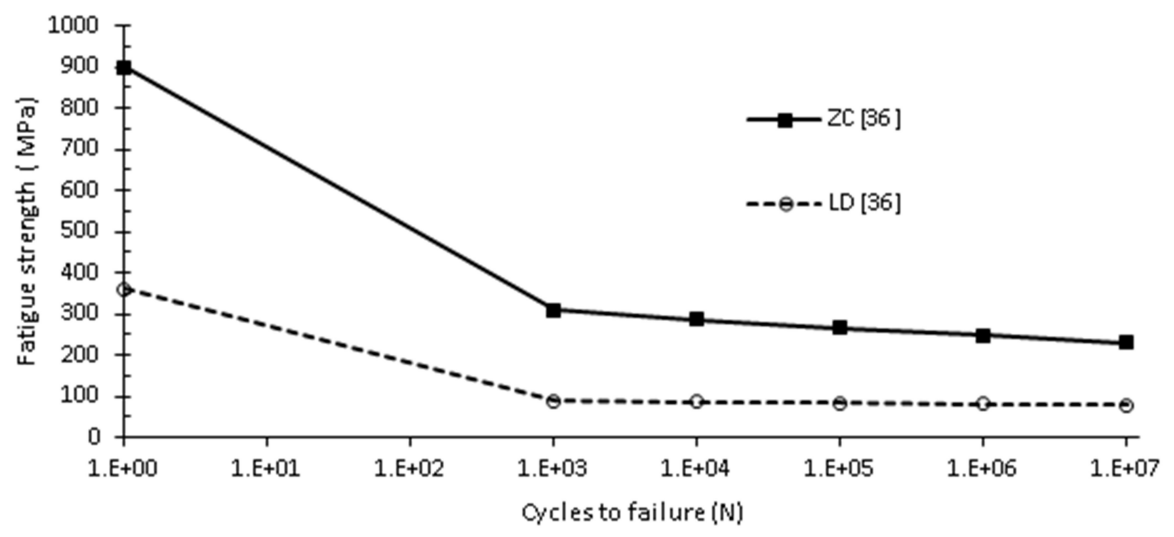

Figure 6 Fatigue strength (S-N curve) for Zirconia and lithium disilicate.

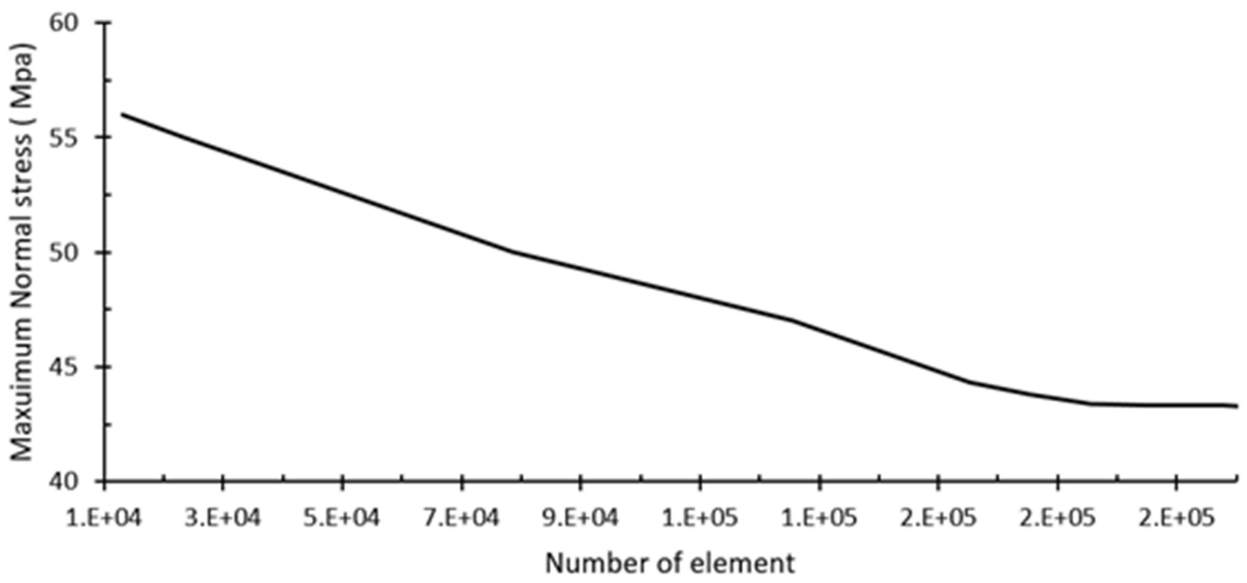

Figure 7 The sensitivity mesh analysis for determining the number of elements.

With the wide use of the advanced technology of CAD/ CAM in dentistry and the introduction of high strength allceramic materials, the trend towards replacing the metal fused to ceramic restorations with the highly aesthetic allceramic materials is growing. ${ }^{58}$ Moreover, the tooth preparation for all-ceramic materials is high in order to leave sufficient thickness for the restored crown to withstand the occlusal forces. In fact, the survival rate of the restored crown is correlated with increased thickness of the crowns. However, minimum reduction of the abutment is required in order to protect the pulp and to increase the retention of the crown. In order to find out the sufficient crown

Table 3 ShowsThe Number of Life Cycles [for Simulating Five Years of Intraoral Use] at Several Fatigue Axial Loads Until Failure. Numbers in Brackets Represent Safety Factor Against Failure for Five Years

\begin{tabular}{|c|c|c|c|c|c|}
\hline \multirow[t]{2}{*}{ Load (N) } & \multirow[t]{2}{*}{ No of Cycles $\left(\mathbf{N}_{\mathrm{f}}\right)$} & \multicolumn{2}{|l|}{ Zirconia } & \multicolumn{2}{|c|}{ Lithium Disilicate } \\
\hline & & $\begin{array}{l}\text { Group A } \\
\text { (Safety Factor) }\end{array}$ & $\begin{array}{l}\text { Group B } \\
\text { (Safety Factor) }\end{array}$ & $\begin{array}{l}\text { Group A } \\
\text { (Safety Factor) }\end{array}$ & $\begin{array}{l}\text { Group B } \\
\text { (Safety Factor) }\end{array}$ \\
\hline 50 & 750,000 & $\begin{array}{l}12,618,449 \\
(13)\end{array}$ & $\begin{array}{l}24,227,422 \\
(15)\end{array}$ & $\begin{array}{l}3,605,271 \\
(4.3)\end{array}$ & $\begin{array}{l}6,922,121 \\
(7.2)\end{array}$ \\
\hline 100 & 590,000 & $\begin{array}{l}2,157,587.52 \\
(5.5)\end{array}$ & $\begin{array}{l}3,883,657 \\
(4.3)\end{array}$ & $\begin{array}{l}653,8 \mid 4,4 \\
(I . I)\end{array}$ & $\begin{array}{l}\mathrm{I}, \mathrm{I} 76,866 \\
(2.4)\end{array}$ \\
\hline 120 & 450,000 & $\begin{array}{l}968,000 \\
(1.5)\end{array}$ & $\begin{array}{l}I, 887,600 \\
(3.5)\end{array}$ & $\begin{array}{l}302,500 \\
\text { (failure) }\end{array}$ & $\begin{array}{l}589,875 \\
(1.3)\end{array}$ \\
\hline
\end{tabular}



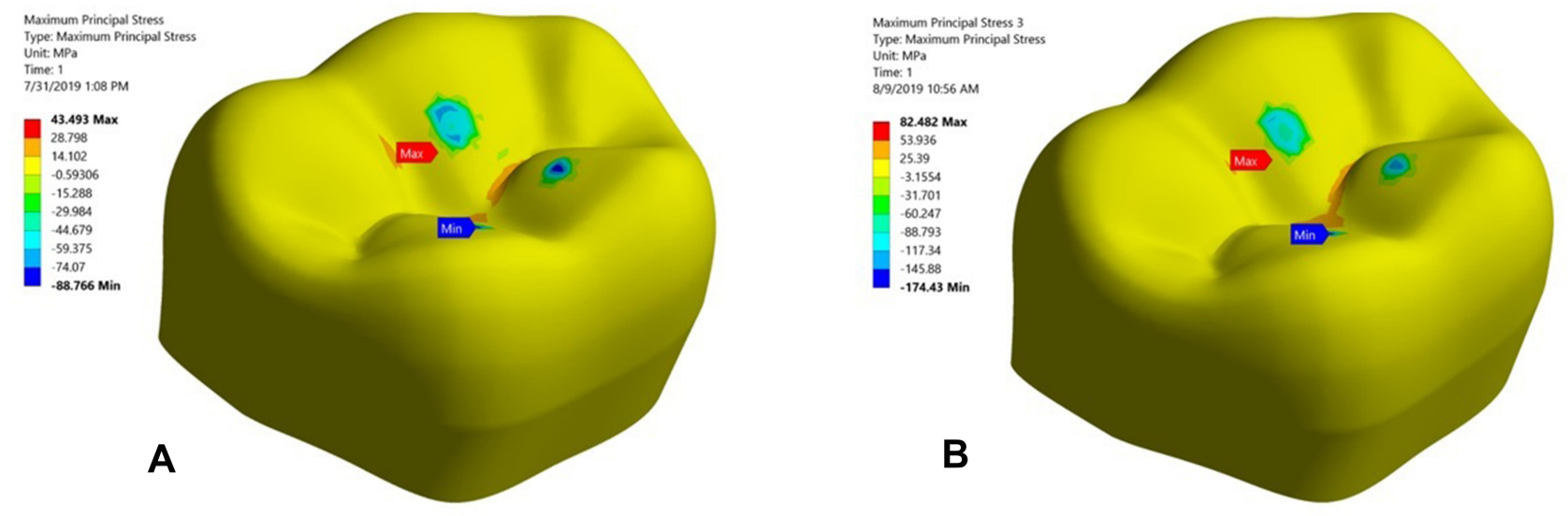

Figure 8 The maximum tensile stress for B groups of Zirconia studied under axial compressive load (A) 50 N; (B) 150 N.
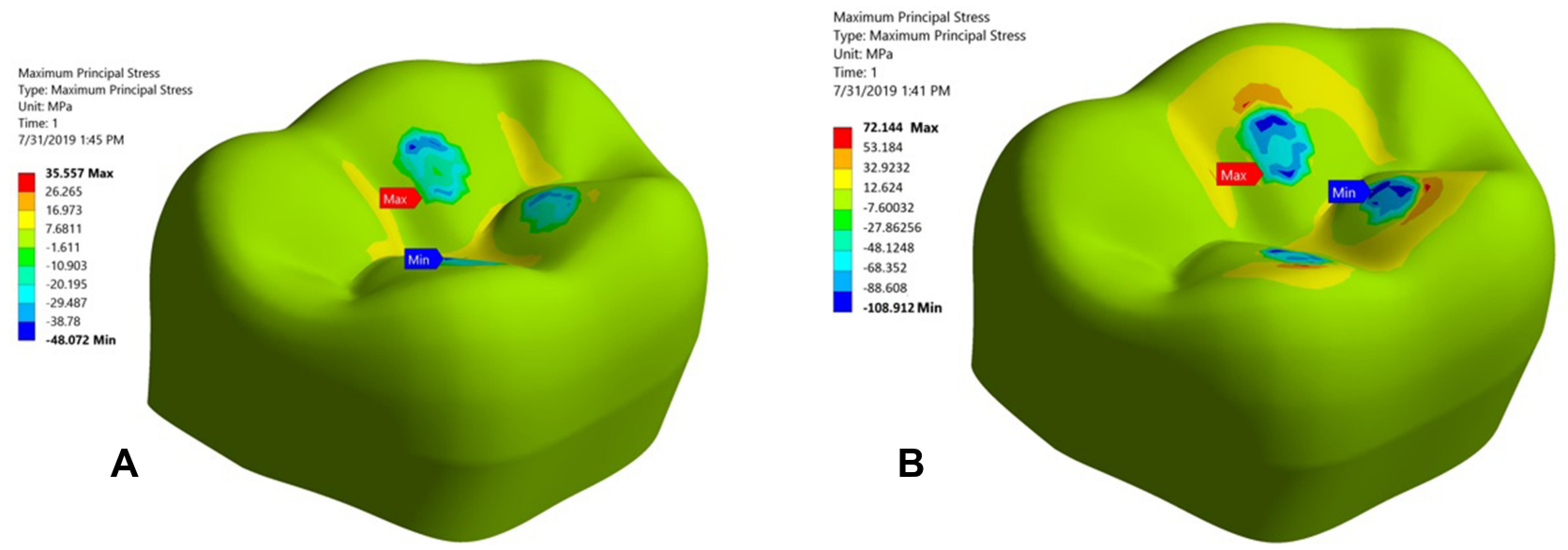

Figure 9 The maximum tensile stress for B groups of lithium disilicate studied under axial compressive load (A) 50 N; (B) I50 N.

thickness that can resist the fatigue stress and survive for short-term (1-5 years) survival rates, this study was conducted using FEA. Two different thin-walled measurements of commonly used dental materials, lithium disilicate and Zirconia, were designed for a single posterior crown. Moreover, the outcome of the short-term clinical survival rates of these materials were also conducted on humans in vivo. ${ }^{59}$

This study confirms that FEA predicts that all-ceramic $\mathrm{CAD} / \mathrm{CAM}$ crowns have sufficient fatigue resistance. The thin-walled crowns (average thickness $1.1 \mathrm{~mm}$ ) of experimental materials have lived longer than five clinical years (under $50 \mathrm{~N}, 100 \mathrm{~N}, 120 \mathrm{~N}$ ) loads. This agrees with a clinical study that reported the lithium disilicate crowns performed well after two years (when teeth were in clinical service) and considered the material to be an effective choice for all-ceramic crowns. ${ }^{60}$ In addition a systematic review indicated that lithium disilicate restorations offer excellent short-term survival rates (1-5 years), but the majority of failures was reported in the posterior region. ${ }^{59}$ A study described the fatigue failure of clinical all-ceramic restorations was generated mainly by the chewing process, and reported the fatigue failure resulted from cracks growing during mastication. ${ }^{61}$

In this study, the factors of safety guarding against fatigue failure indicated that the experimental crowns have large values which imply that invasive tooth preparation can be avoided and this of course is one of the outstanding aims in restorative dentistry.

The current study evaluated the survival rate of crowns in vitro under various cyclic forces using a combination of $\mathrm{S}-\mathrm{N}$ fatigue behavior and FEA to simulate the real behavior in the oral cavity during mastication. This approach has also been used in other studies ${ }^{62-65}$ as avoiding using this approach possibly resulted in a gap between in vitro performance and clinical observations for the materials. ${ }^{49}$ 


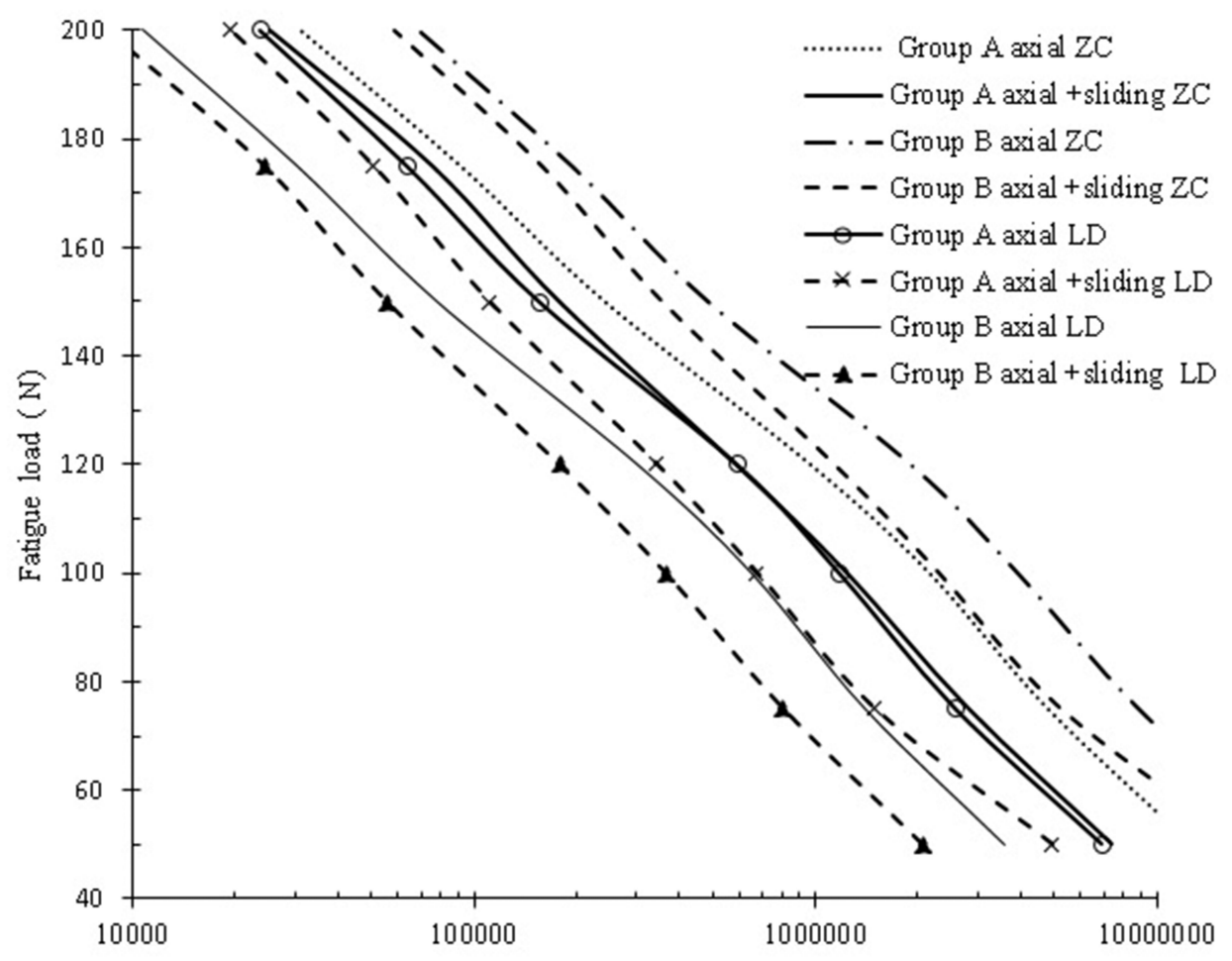

Life cycle

Figure 10 Fatigue life of the experimental crowns tested under two loading conditions; axial loading and axial loading with $0.8 \mathrm{~mm}$ sliding in $\mathrm{Z}$ axis.



Figure II Maximum shear stress at the dentin-adhesive interface at the static load. 
Table 4 Maximum Shear at the Dentin-Adhesive Interface at the Static Load [MPa]

\begin{tabular}{|l|l|l|l|l|}
\hline \multirow{2}{*}{ Load (N) } & \multicolumn{2}{|l|}{ Zirconia } & \multicolumn{2}{l|}{ Lithium Disilicate } \\
\cline { 2 - 5 } & Group A & Group B & Group A & Group B \\
\hline 50 & 3.8 & 3.4 & 3.7 & 3.3 \\
100 & 4.5 & 4.3 & 4.4 & 4.2 \\
\hline
\end{tabular}

However, no significant differences were found $(\mathrm{P}>$ $0.194)$ between the dynamic and static fatigue values for the same surface treatment of Zirconia due to the small number of cycles and the consequently high loading force. $^{66}$

Two types of cyclic fatigue loading were applied in this study; axial loading and axial loading with $0.8 \mathrm{~mm}$ sliding towards the buccal surface. The mechanical loading parameters chosen for this study are comparable to other in vitro studies, ${ }^{67,68}$ and simulated five years of intraoral use. $^{69,70}$ This study showed that applying axial loading with $0.8 \mathrm{~mm}$ sliding on the crowns reduced the expected life of Zirconia and lithium disilicate crowns.

The maximum tensile stress on the crown contour showed three points of contact on the occlusal surface of the crown. Using the spherical indenter in a three cusps loading configuration, distobuccal cusp, mesiolingual cusp and distolingual cusp, FEA successfully predicts the critical regions which have the highest tensile stress are located at the distobuccal cusp. However, a previous study reported the results generated in maximum principal stress show the tensile stress pattern generated in three regions of the prosthetic crown (occlusal face, sagittal cut and internal surface) through a stress map. ${ }^{71}$ A fractographic analysis of fractured crowns and correlation of the maximum tensile stress is presented in Figure 12.
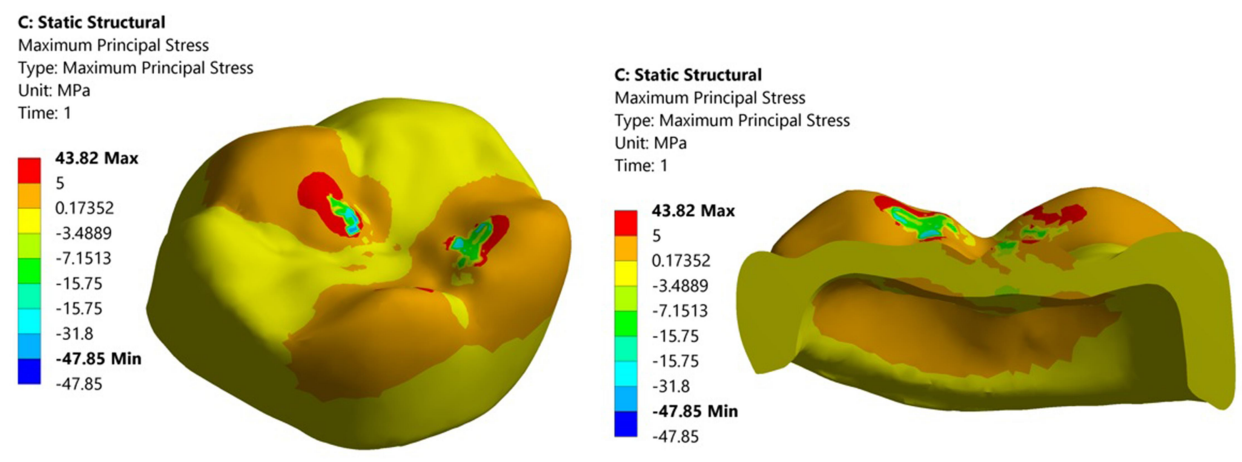

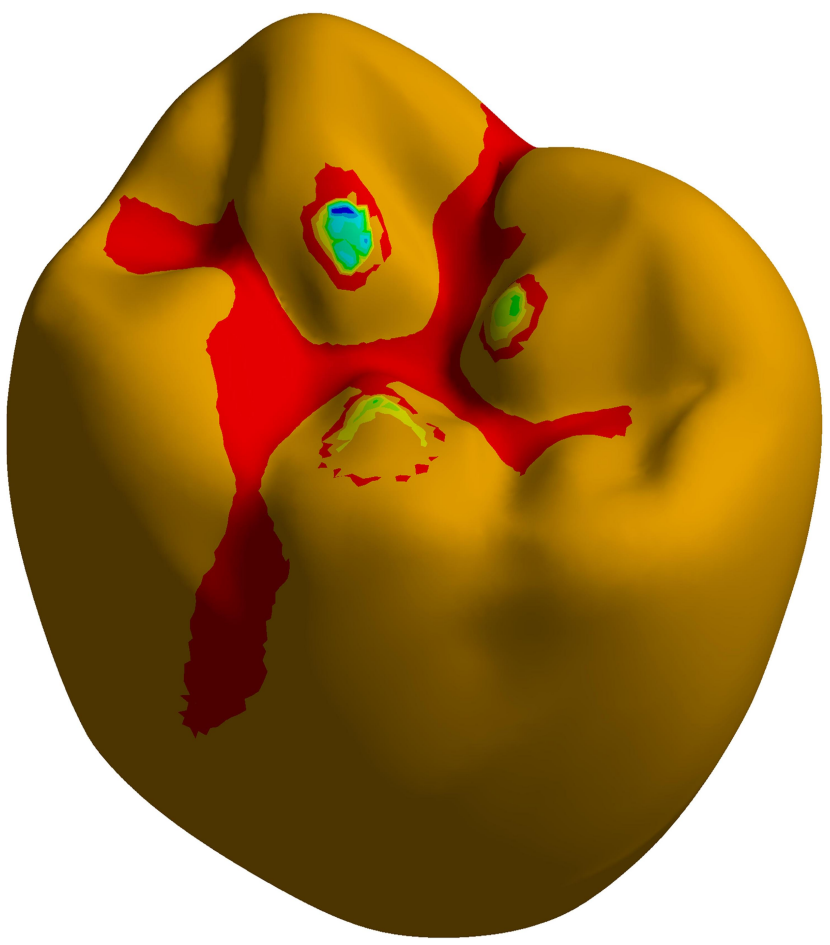

Figure 12 Fractographic of fractured crowns.

Taking into consideration, the brittle characteristics of the experimental $\mathrm{CAD} / \mathrm{CAM}$ materials used in the study, the failure theory confirmed that the maximum tensile stress is responsible for the cracks developing during mastication which finally end in the crown failure. Also, the results confirmed that areas of restored mandibular crowns with minimum thickness that show the highest potential for the initiation of cracks are clearly shown on distobuccal cusp with magnitudes of $0.37 \mathrm{~mm}$ and $1.06 \mathrm{~mm}$ for group A and $\mathrm{B}$, respectively. The radial cracks initiated through the brittle occlusal surface at the central fossa that has the minimum thickness $(0.4 \mathrm{~mm})$ (Figure 13$)$. Those results are valid as long as the restoration is properly seated into position and

Figure 13 Radial cracks on the occlusal surface. 
a strong adhesion between the abutments and crown is present, and an even luting cement film thickness of $\sim 25-50 \mu \mathrm{m}$ at the margin is guaranteed to achieve marginal accuracy and ensure clinical reliability.

Further studies are required using FEA on other newly developed materials and validation of FEA results by conducting in vivo experimentation, as well as FEA using different types and parameters of cement-adhesive materials and various crown materials.

\section{Conclusion}

The fatigue strength of Zirconia shows superior performance compared with lithium disilicate. The fatigue life for the Zirconia and lithium disilicate crowns with thickness $1.1 \mathrm{~mm}$ exceeded five clinical years under axial load of 120 $\mathrm{N}$. For all models studied, the maximum principal stresses are located at the distobuccal cusp of the occlusal surface.

\section{Acknowledgments}

The study was supported by Deanship of Research at Jordan University of Science and Technology.

\section{Disclosure}

The authors report no conflicts of interest in this work.

\section{References}

1. Rosenstiel SF, Land MF, Fujimoto J. Contemporary Fixed Prosthodontics. St. Louis, MO: Mosby; 2001:262-271.

2. Sjogren G, Sletten G, Dahl JE. Cytotoxicity of dental alloys, metals, and ceramics assessed by millipore filter, agar overlay, and MTT tests. J Prosthet Dent. 2000;84:229-236. doi:10.1067/mpr.2000.107227

3. Siervo S, Pampalone A, Siervo P, et al. Where is the gap? Machinable ceramic systems and conventional laboratory restorations at a glance. Quintessence Int. 1994;25:773-779.

4. Blatz MB. Long-term clinical success of all-ceramic posterior restorations. Quintessence Int. 2002;33:415-426.

5. Chen C, Trindade FZ, de Jager N, Kleverlaan CJ, Feilzer AJ. The fracture resistance of a CAD/CAM Resin Nano Ceramic (RNC) and a CAD ceramic at different thicknesses. Dent Mater. 2014;30: 954-962. doi:10.1016/j.dental.2014.05.018

6. Li Y, Chen J, Liu J, Zhang L, Wang W, Zhang S. Estimation of the reliability of all-ceramic crowns using finite element models and the stress-strength interference theory. Comput Biol Med. 2013;43: 1214-1220. doi:10.1016/j.compbiomed.2013.06.007

7. Pjetursson BE, Sailer I, Zwahlen M, Hammerle CH. A systematic review of the survival and complication rates of all-ceramic and metal ceramic reconstructions after an observation period of at least 3 years. Part I: single crowns. Clin Oral Implants Res. 2007;18 (3):73-85. doi:10.1111/j.1600-0501.2007.01467.x

8. Denry I, Kelly JR. State of the art of zirconia for dental applications. Dent Mater. 2008;24(3):299-307. doi:10.1016/j.dental.2007.05.007

9. Guess PC, Silva NR, Bonfante EA, Coelho PG, Thompson VP. Monolithic CAD/CAM lithium disilicate versus veneered Y-TZP crowns: comparison of failure modes and reliability after fatigue. Int J Prosthodont. 2010;23:434-442.
10. Rekow ED, Silva N, Coelho PG, Zhang Y, Guess P, Thompson VP. Performance of dental ceramics: challenges for improvements. J Dent Res. 2011;90:937-952. doi:10.1177/0022034510391795

11. Lung CYK, Botelho MG, Heinonen M, Matinlinna JP. Resin zirconia bonding promotion with some novel coupling agents. Dent Mater. 2012;28:863-872.

12. Biscaro L, Bonfiglioli R, Soattin M, Vigolo P. An in vivo evaluation of fit of zirconium-oxide based ceramic single crowns, generated with two CAD/CAM systems, in comparison to metal ceramic single crowns. J Prosthodont. 2013;22:36-41. doi:10.1111/j.1532-849X.20 12.00907.x

13. Chu SJ. Current clinical strategies with lithium-disilicate restorations. Compend Contin Educ Dent. 2012;33:64-67.

14. Tan PL, Dunne JT. An esthetic comparison of a metal ceramic crown and cast metal abutment with an all-ceramic crown and zirconia abutment: a clinical report. J Prosthet Dent. 2004;91:215-218. doi:10.1016/j.prosdent.2003.12.024

15. Kosmac T, Oblakb C, Jevnikarb P, Fundukb N, Marion L. The effect of surface grinding and sandblasting on flexural strength and reliability of Y-TZP zirconia ceramic. Dent Mater. 1999;15:426-433. doi:10.1016/S0109-5641(99)00070-6

16. Al-Dohan HM, Yaman P, Dennison JB, Razzoog ME, Lang BR. Shear strength of core-veneer interface in bi-layered ceramics. J Prosthet Dent. 2004;91:349-355. doi:10.1016/j.prosdent.2004.02.009

17. Junctive N, Sirisathit I. Marginal accuracy of computer-aided designand computer-aided manufacturing-fabricated full-arch zirconia restoration. Clin Cosmet Investig Dent. 2018;15(10):9-17.

18. Millen CS, Reuben RL, Ibbetson RJ. The effect of coping/veneer thickness on the fracture toughness and residual stress of implant supported, cement retained zirconia and metal ceramic crowns. Dent Mater. 2012;28(10):e250-e258. doi:10.1016/j.dental.2012.06.008

19. White SN, Miklus VG, McLaren EA, et al. Flexural strength of a layered zirconia and porcelain dental all-ceramic system. J Prosthet Dent. 2005;94:125-131. doi:10.1016/j.prosdent.2005.05. 007

20. Duan Y, Griggs JA. Effect of elasticity on stress distribution in CAD/ CAM dental crowns: glass ceramic vs. polymer-matrix composite. J Dent. 2015;43:742-749. doi:10.1016/j.jdent.2015.01.008

21. Adolf D, Tribst JPM, Adolfi M, Dal Piva AMO, Saavedra GSFA, Bottino MA. Lithium disilicate crown, zirconia hybrid abutment and platform switching to improve the esthetics in anterior region: a case report. Clin Cosmet Investig Dent. 2020;19(12):31-40. doi:10.2147/ CCIDE.S234980

22. Carvalho AO, Bruzi G, Giannini M, Magne P. Fatigue resistance of $\mathrm{CAD} / \mathrm{CAM}$ complete crowns with a simplified cementation process. J Prosthet Dent. 2014;111:310-317. doi:10.1016/j.prosdent.2013.09. 020

23. Alhasanyah A, Vaidyanathan T, Flinton R. Effect of core thickness differences on post-fatigue indentation fracture resistance of veneered zirconia crowns. J Prosthodont. 2013;22(5):383-390. doi:10.1111/ jopr.12016

24. Lameira DP, Buarque e Silva WA, Andrade e Silva F, De Souza GM. Fracture strength of aged monolithic and bilayer zirconia-based crowns. Biomed Res Int. 2015;418641.

25. Podhorsky A, Rehmann P, Wöstmann B. Tooth preparation for fullcoverage restorations - a literature review. Clin Oral Investig. 2015;19:959-996. doi:10.1007/s00784-015-1439-y

26. Jalalian E, Atashkar B, Rostami R. The effect of preparation design on the fracture resistance of zirconia crown copings (computer associated design/computer associated machine, CAD/CAM system). $J$ Dent (Tehran). 2011;8(3):123-129.

27. Rosenstiel SF, Land MF, Fujimoto J. Contemporary Fixed Prosthodontics. 4th ed. St. Louis: Mosby Elsevier; 2006.

28. Shillingburg HT, Hobo S, Whitsett LD, Jacobi R, Brackett SE. Fundamentals of Fixed Prosthodontics. 3rd ed. Carol Stream: Quintessence; 1997. 
29. Goodacre CJ, Campagni WV, Aquilino SA. Tooth preparations for complete crowns: an art form based on scientific principles. J Prosthet Dent. 2001;85(4):363-376. doi:10.1067/mpr.2001.114685

30. Parker MH, Calverley MJ, Gardner FM, Gunderson RB. New guidelines for preparation taper. $J$ Prosthodont. 1993;2(1):61-66. doi:10.1111/j.1532-849X.1993.tb00383.x

31. Weed RM, Baez RJ. A method for determining adequate resistance form of complete cast crown preparations. J Prosthet Dent. 1984;52 (3):330-334. doi:10.1016/0022-3913(84)90437-2

32. Chan DC, Chung AK, Haines J, Yau EH, Kuo CC. The accuracy of optical scanning: influence of convergence and die preparation. Oper Dent. 2011;36(5):486-491. doi:10.2341/10-067-L

33. Chan DC, Wilson AH, Barbe P, Cronin RJ, Chung C, Chung K. Effect of preparation convergence on retention and seating discrepancy of complete veneer crowns. J Oral Rehabil. 2005;32(1):58-64. doi:10.1111/j.1365-2842.2004.01371.x

34. Wilson AH, Chan DC. The relationship between preparation convergence and retention of extracoronal retainers. J Prosthodont. 1994;3 (2):74-78. doi:10.1111/j.1532-849X.1994.tb00132.x

35. Corazza PH, Feitosa SA, Borges AL, Della Bona A. Influence of convergence angle of tooth preparation on the fracture resistance of Y-TZP-based all-ceramic restorations. Dent Mater. 2013;29 (3):339-347. doi:10.1016/j.dental.2012.12.007

36. Proos KA, Swain MV, Ironside J, Steven GP. Influence of margin design and taper abutment angle on a restored crown of a first premolar using finite element analysis. Int J Prosthodont. 2003;16 (4):442-449.

37. Sornsuwan T, Swain MV. The effect of margin thickness, degree of convergence and bonding interlayer on the marginal failure of glass-simulated all-ceramic crowns. Acta Biomater. 2012;8 (12):4426-4437. doi:10.1016/j.actbio.2012.08.006

38. Boitelle P, Mawussi B, Tapie L, Fromentin O. A systematic review of CAD/CAM fit restoration evaluations. J Oral Rehabil. 2014;41 (11):853-874.

39. Holmes JR, Bayne SC, Holland GA, Sulik WD. Considerations in measurement of marginal fit. J Prosthet Dent. 1989;62(4):405-408. doi:10.1016/0022-3913(89)90170-4

40. Anusavice JL, Shen C, Rawls HR. Philips Materiais Dentários. 12th ed. Rio de Janeiro: Elsevier; 2013.

41. Nakamura K, Harada A, Inagaki R, et al. Fracture resistance of monolithic zirconia molar crowns with reduced thickness. Acta Odontol Scand. 2015;73:602-608. doi:10.3109/00016357.2015.10 07479

42. Nakamura K, Mouhat M, Nergård JM, et al. Effect of cements on fracture resistance of monolithic zirconia crowns. Acta Biomater Odontol Scand. 2016;2:12-19. doi:10.3109/23337931.2015.1129908

43. Sorrentino R, Triulzio C, Tricarico MG, Bonadeo G, Gherlone EF, Ferrari M. In vitro analysis of the fracture resistance of CAD-CAM monolithic zirconia molar crowns with different occlusal thickness. J Mech Behav Biomed Mater. 2016;61:328-333. doi:10.1016/j. jmbbm.2016.04.014

44. Thompson VP, Rekow DE. Dental ceramics and the molar crown testing ground. J Appl Oral Sci. 2004;12:26-36. doi:10.1590/S167877572004000500004

45. Sun T, Zhou S, Lai R, et al. Load-bearing capacity and the recommended thickness of dental monolithic zirconia single crowns. $J$ Mech Behav Biomed Mater. 2014;35:93-101. doi:10.1016/j. jmbbm.2014.03.014

46. Papia E, Larsson C, Du Toit M, Vult von Steyern P. Bonding between oxide ceramics and adhesive cement systems: a systematic review. J Biomed Mater Res B Appl Biomater. 2014;102:395-413. doi:10.10 02/jbm.b.33013

47. Weigl P, Sander A, Wu Y, Rosentritt M, Lauer H, Rosentritt M. Invitro performance and fracture strength of thin monolithic zirconia crowns. J Adv Prosthodont. 2018;10(2):79-84. doi:10.4047/jap.2018. 10.2.79
48. Nihioka G, Prochnow C, Firmino A, et al. Fatigue strength of several dental ceramics indicated for CAD-CAM monolithic restorations. Braz Oral Res. 2018;11(32):53.

49. Dejak B, Młotkowski A, Langot C. Three-dimensional finite element analysis of molars with thin-walled prosthetic crowns made of various materials. Dent Mater. 2012;28(4):433-441. doi:10.1016/j. dental.2011.11.019

50. Att W, Kurun S, Gerds T, Strub JR. Fracture resistance of single-tooth implant-supported all-ceramic restorations: an in vitro study. $J$ Prosthet Dent. 2006;95:111-116. doi:10.1016/j.prosdent.2005.12.003

51. Ausiello P, Ciaramella S, Martorelli M, et al. Mechanical behavior of endodontically restored canine teeth: effects of ferrule, post material and shape. Dent Mater. 2017;33:1466-1472. doi:10.1016/j. dental.2017.10.009

52. Dal Piva AMO, Tribst JPM, Souza ROAE, Borges ALS. Influence of alveolar bone loss and cement layer thickness on the biomechanical behavior of endodontically treated maxillary incisors: a 3-dimensional finite element analysis. J Endod. 2017;43:791-795. doi:10.1016/j.joen.2016.11.020

53. Monteiro JB, Dal Piva AMO, Tribst JPM, Borges ALS, Tango RN. The effect of resection angle on stress distribution after root-end surgery. Iran Endod J. 2018;13:188-194.

54. Ausiello P, Ciaramella S, Martorelli M, Lanzotti A, Gloria A, Watts DC. CAD-FE modeling and analysis of class II restorations incorporating resin-composite, glass ionomer and glass ceramic materials. Dent Mater. 2017;33:1456-1465. doi:10.1016/j.dental.2017.10.010

55. Santiago JF, Verri FR, Almeida DA, Souza Batista VE, Lemos CA, Pellizzer EP. Finite element analysis on influence of implant surface treatments, connection and bone types. Mater Sci Eng C Mater Biol Appl. 2016;63:292-300. doi:10.1016/j.msec.2016.02.061

56. Vichi A, Sedda M, Fonzar R, Carrabba M, Ferrari M. Comparison of contrast ratio, translucency parameter, and flexural strength of traditional and "augmented translucency" zirconia for CEREC CAD/ CAM system. J Esthet Restor Dent. 2016;28:S32-S39. doi:10.1111/ jerd. 12172

57. Eazhil R, Swaminathan S, Madhan G, Kannan V, Alagesan C. Impact of implant diameter and length on stress distribution in osseointegrated implants: a 3D FEA study. J Int Soc Prev Commun Dent. 2016;6:590-596. doi:10.4103/2231-0762.195518

58. Batson ER, Cooper LF, Duqum I, Mendonça G. Clinical outcomes of three different crown systems with CAD/CAM technology. J Prosthet Dent. 2014;112:770-777.

59. Pieger S, Salman A, Bidra AS. Clinical outcomes of lithium disilicate single crowns and partial fixed dental prostheses: a systematic review. J Prosthet Dent. 2014;112(1):22-30. doi:10.1016/j.prosdent.2014.01.005

60. Fasbinder DJ, Dennison JB, Heys D, Neiva G. A clinical evaluation of chairside lithium disilicate CAD/CAM crowns: a two-year report. $J$ Am Dent Assoc. 2010;141:10S-14S. doi:10.14219/jada.archive.20 10.0355

61. Pogoncheff CM, Duff RE. Use of zirconia collar to prevent interproximal porcelain fracture: a clinical report. $J$ Prosthet Dent. 2010;104:77-79. doi:10.1016/S0022-3913(10)60095-9

62. Homaei E, Farhangdoost K, Tsoi J, Matinlinna J, Pow E. Static and fatigue mechanical behavior of three dental CAD/CAM ceramics. $J$ Mech Behav Biomed Mater. 2016;59:304-313. doi:10.1016/j. jmbbm.2016.01.023

63. Homaei E, Jinc X, Pow E, Matinlinn J, Tsoic J, Farhangdoost K. Numerical fatigue analysis of premolars restored by CAD/CAM ceramic crowns. Dent Mater. 2018;34(7):149-157.

64. Zhang L, Wang Z, Chen J, Zhou W, Zhang S. Probabilistic fatigue analysis of all-ceramic crowns based on the finite element method. J Biomech. 2010;43:2321-2326. doi:10.1016/j.jbiomech.2010.04.030

65. Vukicevic AM, Zelic K, Jovicic G, Djuric M, Filipovic N. Influence of dental restorations and mastication loadings on dentine fatigue behaviour: image-based modelling approach. J Dent. 2015;43:55 6-567. doi:10.1016/j.jdent.2015.02.011 
66. Aboushelib MA, Wang H, Kleverlaan CJ, Albert Feilzer AJ. Fatigue behavior of zirconia under different loading conditions. Dent Mater. 2016;32(7):915-920. doi:10.1016/j.dental.2016.03.012

67. Abouelleil H, Jeannin C, Amadou Sadat A, Grosgogeat B. Development of a chewing simulator for testing dental materials: a pilot study. Br J Appl Sci Technol. 2015;5(1):1-8. doi:10.9734/ BJAST/2015/13003

68. Rosentritt M, Behr M, van der Zel JM, Feilzer AJ. Approach for evaluating the influence of laboratory simulation. Dent Mater. 2009;25:348-352. doi:10.1016/j.dental.2008.08.009

69. Rosentritt M, Siavikis G, Behr M, Kolbeck C, Handel G. Approach for evaluating the significance of laboratory simulation. J Dent. 2008;361048-361053.
70. Rosentritt M, Steiger D, Behr M, Handel G, Kolbeck C. Influence of substructure design and spacer settings on the in vitro performance of molar zirconia crowns. J Dent. 2009;37:978-983. doi:10.1016/j. jdent.2009.08.003

71. Dal Piva AMO, Tribst JPM, Borges ALS, Souza ROAE, Bottino MA. CAD-FEA modeling and analysis of different full crown monolithic restorations. Dent Mater. 2018;34(9):1342-1350. doi:10.1016/j. dental.2018.06.024

\section{Publish your work in this journal}

Clinical, Cosmetic and Investigational Dentistry is an international, peer-reviewed, open access, online journal focusing on the latest clinical and experimental research in dentistry with specific emphasis on cosmetic interventions. Innovative developments in dental materials, techniques and devices that improve outcomes and patient satisfaction and preference will be highlighted. The manuscript management system is completely online and includes a very quick and fair peer-review system, which is all easy to use. Visit http://www.dovepress.com/testimonials.php to read real quotes from published authors. 